Criar Educação, Criciúma, v. 9, no 3, ago/dez. 2020 - PPGE - UNESC - ISSN 2317-2452

\title{
CATATAU: DE DESCARTES A CARTESIUS EDUCANDO PARA A SENSIBILIDADE
}

Resumo: Considerando o potencial diálogo entre a literatura e a educação na perspectiva do educar para a sensibilidade, o presente trabalho objetivo analisar fragmentos da obra literária Catatau, do poeta Paulo Leminski, buscando estabelecer relação com a educação para a sensibilidade. Nesse contexto, empreende tal análise à luz dos conceitos de rizoma, voz e $(m)$ performance e educação menor, a partir dos referenciais teóricos de Gilles Deleuze e Félix Guattari, Paul Zumthor e Silvio Gallo, respectivamente. Dentre os resultados, verifica-se que a linguagem metafórica de Catatau é consonante com a educação para a sensibilidade circunscrita na educação menor. Espera-se, desse modo, contribuir para desvelar o potencial das experiências que ultrapassem uma racionalidade que, por vezes, não contempla a rica articulação entre o signo poético presente na arte literária e a educação.

Palavras-chave: Catatau, rizoma, educação, voz e $(\mathrm{m})$ performance

\section{CATATAU: FROM DISCARDES TO CARTESIUS EDUCATING FOR SENSITIVITY}

Abstract: Considering the potential dialogue between literature and education as a means to educate towards sensitivity, this work aims at analyzing excerpts from Catatau, by poet Paulo Leminski, in order to relate it with education towards sensitivity. Therefore, this analysis is based on the concepts of rhizome, voice in/and performance and minor education, by Gilles Deleuze and Félix Guattari, Paul Zumthor, and Silvio Gallo, respectively. Among the results, it is possible to observe that the metaphorical language of Catatau is in line with education towards sensitivity within minor education. Thus, we expect to contribute and unveil the potential of experiences that go beyond reasonability which, often times, does not cover the rich articulation between the poetic signs of literary art and education.

Keywords: Catatau, rhizome, education, voice in/and performance.

\footnotetext{
1 Universidade Federal de Lavras. Cx. Postal 3037, CEP 37200-900 - Lavras (MG) - email: dalva.lobo@ufla.br
} 


\section{Considerações iniciais}

O texto escrito, não mais me entendi naquela artimanha. [...]Meti números no corpo e era esgrima, números nas coisas e era ciência, números nos verbos e era poesia. (Catatau, 1989, p. 30)

Diante da angústia do efêmero o homem buscou preservar sua história transmitindo suas experiências por meio de linguagens que o eternizassem. Desse modo, constituiu as memórias às quais recorremos eventualmente porque, de algum modo, elas nos remetem à nossa humanidade mesma.

Sobre tais linguagens, desde a oralidade, marcada pela dimensão do coletivo e pelas artes de contar histórias que teciam os fios do passado àquela realidade, fosse pela voz da comunidade fosse pela dos rapsodos e aedos, entre outros poetas, notamos o quanto reiteramos e transformamos costumes e tradições num processo dinâmico que atualiza nosso modus vivendi.

Nesse contexto, é pertinente dizer que nos territórios da linguagem estão implicados fatores históricos, sociais e culturais, ou, dito de outro modo, a linguagem na qual a língua e, por conseguinte, a taxonomia linguística estão contidas, é o espaço em que nos constituímos como sujeitos. Por isso, falar de tais territórios tem a ver com compreender os códigos cada vez mais complexos que se transformam, desaparecem ou são assimilados por outros.

De modo semelhante, o educar passa pelos mesmos fatores, sendo potencializado pelas diferentes perspectivas e solicita o despertar da sensibilidade para que novas formas de conhecer se constituam holisticamente. Nessa perspectiva, é oportuno apontar para o fato de que o discurso ficcional implica linguagem mais aberta a interpretações que podem ultrapassar a taxonomia linguística e a rigidez discursiva produzida por enunciados cristalizados, tornando-se signo de fazer e abstrair.

Diante disso, o presente artigo, compreendendo que os processos implicados na expansão da linguagem são da ordem da migração por territórios do inusitado, 
Criar Educação, Criciúma, v. 9, no 3, ago/dez. 2020 - PPGE - UNESC - ISSN 2317-2452

pretende discutir a produção desses territórios a partir da literatura, aqui representada pela obra Catatau, do poeta curitibano Paulo Leminski.

Assim, a questão que orienta a presente reflexão é como o inusitado da língua, da linguagem e do pensamento a que remete a obra literária, se rizomatiza para outros territórios, desvelando, assim, o potencial criativo da educação, sobretudo no que toca à sensibilidade? A hipótese é de que a obra literária dialoga com a proposta de um educar para a sensibilidade, tendo em vista que o inusitado e as aporias constituem desafios capazes de trazer à tona o que o ser humano possui de mais atávico, a saber, sua capacidade criativa.

Nessa perspectiva, nos limites propostos para esse diálogo, serão analisados fragmentos da narrativa de Catatau, à luz dos conceitos de rizoma, de voz e(m) performance, e educação menor, fundamentados em Deleuze e Guatarri, Paul Zumthor e Silvio Gallo, respectivamente.

Para fins metodológicos, primeiramente será apresentado o contexto da obra literária visando explicitar como se constitui a linguagem narrativa, cujos fragmentos serão analisados à luz dos conceitos elencados. Num segundo momento, os fragmentos serão relacionados com a educação para a sensibilidade.

A obra Catatau, publicada primeiramente em 1975, nasceu durante uma aula de história ministrada por Leminski, na qual cogitou a possibilidade de o filósofo René Descartes ter realmente vindo ao Brasil com Maurício de Nassau, durante as invasões holandesas. Partindo de tal hipótese, o poeta desenvolveu uma narrativa cuja linguagem opera transgressões de linguagem e de pensamento por parte do personagem Renatus Cartesius, uma espécie de ego parodiado do filósofo francês, quando nos trópicos pernambucanos. Com uma segunda edição, publicada quatorze anos depois, em 1989, a obra contou com comentários de seu autor e fortuna crítica de poetas e escritores, entre os quais Haroldo de Campos, José Antonio Risério, Bóris Schnaiderman e Régis Bonvicino.

Em Catatau, os supostos desvarios de linguagem e do pensamento decorrem do fato de o personagem desenvolver outras percepções sobre o que compreendia como conhecimento antes de desembarcar no Brasil, cujo contexto desconhecia, tanto em termos de linguagem quanto de visão de mundo. 
Criar Educação, Criciúma, v. 9, no 3, ago/dez. 2020 - PPGE - UNESC - ISSN 2317-2452

Considerando nossa contemporaneidade, Catatau dialoga com a questão do despertar para a sensibilidade e para a expansão de nossa linguagem para outros territórios, e, sobremodo no que diz respeito à educação, tal diálogo pressupõe a busca por experiências educativas inovadoras que superem a racionalidade instrumental.

Com base nessas considerações iniciais, sem esgotar o tema, espera-se contribuir para o despertar de uma sensibilidade que possa atribuir novos significados à linguagem e ao pensamento e, nesse contexto, contribuir para uma educação que traga à tona, cada vez mais, nossa humanidade e potencial criativo.

\section{1 - Catatau: um mundo de aporias deleitosas}

Nascido sob o signo do quiproquó (1989), como afirmou Paulo Leminski, Catatau é animado por dois movimentos: o introverso, no qual o personagem histórico transmutará no ego parodiado Renatus Cartesius, e o extroverso, em que o personagem inicialmente, agônico, frustrado e ao mesmo tempo excitado com universo tropical, buscará nas teias do diálogo nonsense pontos nodais para se ancorar tentando manter intacta a lógica discursiva.

Diante da possibilidade de que o filósofo René Descartes tivesse acompanhado o então onde João Maurício de Nassau durante as invasões holandesas, no período de 1630 a 1654, surge a inquietação sobre qual seria o olhar de Descartes sobre os trópicos, tão diferentes de sua realidade. A começar pela profusão de cores e sons oriundos da fauna e flora brasileiras, a hipótese do poeta era de que ambas afetariam a racionalidade cartesiana, cedendo lugar ao pensamento mais fluido.

É desse modo que surge o personagem Renatus Cartesius, um ego parodiado, cuja metamorfose se configura pelo conflito entre a racionalidade que explicaria os fenômenos e a profusão de informações (signos) dos trópicos brasileiros para os quais as lentes de luneta (racionalidade cartesiana) não encontram respostas plausíveis. 


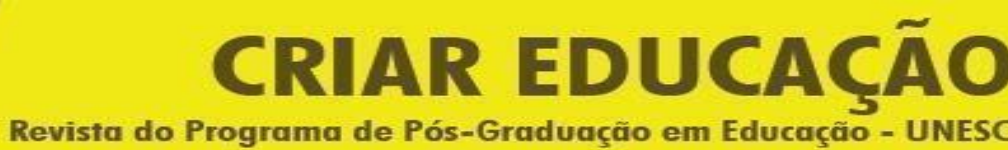

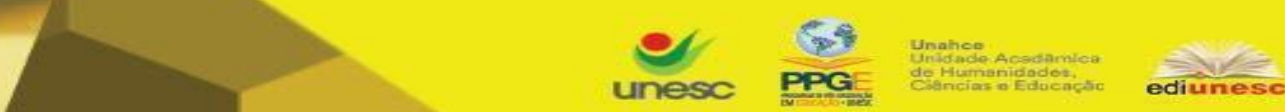

Criar Educação, Criciúma, v. 9, no 3, ago/dez. 2020 - PPGE - UNESC - ISSN 2317-2452

É oportuno trazer o significado do nome Renatus, do latim, renascido, e, por analogia, Cartesius/Descartes renascido, conotando o renascimento do personagem ou a constante metamorfose que opera a partir da angústia gerada por constatar o fracasso da lógica cartesiana no calor tropical.

Sua verborragia, decorrente de percepções outras diante do inusitado e do insólito ambiente, se assentará na experiência imediata com os objetos e com a linguagem fronteiriça que obrigará o personagem, ao menos inicialmente, a reorganizar o cogito. Contudo, sua trajetória errática o levará para um labirinto no qual importa menos compreender do que experimentar.

Vejamos as primeiras impressões do personagem nos trópicos brasileiros, que ele inicia dizendo:

ergo sum, aliás, Ego sum Renatus Cartesius, cá perdido, aqui presente, neste labirinto de enganos deleitáveis, - vejo o mar, vejo a baía e vejo as naus. Vejo mais. Já lá vão anos III me destaquei de Europa e a gente civil, lá morituro. Isso de "barbarus - non intellegor ulli" - dos exercícios de exílio de Ovídio é comigo. Do parque do príncipe à lentes de luneta, CONTEMPLO A CONSIDERAR O CAIS, O MAR, AS NUVENS, OS ENIGMAS E OS PRODÍGIOS DE BRASÍLIA . [...]. O olho cresce lentes sobre coisas, o mundo despreparado para essa aparição do olho, onde passeia não cresce mais luz, onde faz deserto, chamam paz.[...]. Não sou máquina, não sou bicho, sou René Descartes, com a graça de Deus. Ao inteirar-me disso, estarei inteiro. (LEMINSKI, 1989, os.13, 16 -27)

Nota-se no excerto acima o impacto causado pela realidade imediata no pensamento do personagem. O "ergo sum", isto é, o "portanto sou" se dilui na primeira frase, substituído por "Ego", ou seja, "eu" sou.

A utilização da letra maiúscula, comum em início de frase, só ocorre a seguir, conotando que o advérbio conclusivo, "portanto", o qual, linguisticamente, encerra um pensamento anunciando uma dedução após estudo ou pesquisa, é substituído pelo sou, esse sim, iniciado em a letra "E" em maiúscula, como se o personagem estivesse pensando a partir de um novo olhar, ainda que sob o impacto tropical.

Outro ponto é a grafia em caixa alta, como se metaforizando as lentes da luneta com a qual observa o cenário, atingindo, inclusive, Brasília, o que não seria possível considerando que está em Recife. 
Criar Educação, Criciúma, v. 9, no 3, ago/dez. 2020 - PPGE - UNESC - ISSN 2317-2452

Não menos importante é o despreparo diante dos signos do novo mundo que o faz buscar inteirar-se de ser Descartes, apontando já uma dúvida quanto ao método de observação, no caso, a luneta, único objeto de que dispõe no parque do príncipe, uma alusão ao conde Mauricio de Nassau que depois se tornou príncipe. Assim, os signos do espaço no qual o personagem vivencia sua trajetória errática geram mais dúvidas do que certezas, por isso, Descartes não conhece mais Descartes. Seguindo com a elucubração, Cartesius reconhece, então, estar em um labirinto de enganos, porém, deleitáveis.

Os elementos linguísticos representam o olhar sobre a experiência insólita vivida pelo personagem e responsável por sua transformação. Enquanto transita pelos labirintos de uma linguagem cada vez mais movente, Cartesius cria novas ambiências $^{2}$, ou seja, novos espaços nos quais pode experimentar várias articulações sem relação de subordinação, mas de uma livre migração entre diferentes códigos, seja pela questão linguística, seja pela do pensamento, ambas comprometidas nos trópicos brasileiros.

Tais ambiências e labirintos de linguagem remetem ao rizoma, o qual,

Põe em jogo regimes de signos muito diferentes, inclusive estados de não-signos. O rizoma não se deixa reconduzir nem ao Um nem ao múltiplo. Ele não é o Uno que se torna dois, nem o múltiplo que deriva do Uno. Ele não tem começo nem fim, mas sempre um meio pelo qual cresce. (DELEUZE E GUATTARI, 1995, p.32).

No caso do personagem, o rizoma se constitui a partir das incertezas diante do fracasso da lógica que compromete o dizer e o pensar, não mais inteligíveis porque não mais submetidos ao método. Por isso, dirá Cartesius:

Dou por perdido aquele instante, pedra preciosa no tesouro das cronologias. Que signos abriram as cortinas que separavam meus métodos das tentações dos deuses destas paragens? [...]. Ocorreme o seu pensa ainda.... Homem escrito pensa? Esse pensamento,

\footnotetext{
20 conceito de ambiências aqui apresentado, foi desenvolvido pelo professor e pesquisador Wilton de Azevedo e trata de designar um ambiente no qual a escritura poética se expande em função das inúmeras articulações advindas das experimentações e mutações dos códigos em constante migração, sem necessidade de uma matriz para seu registro, já que transitam num espaço em que a relação tempo e espaço se faz parataticamente. Segundo Azevedo, a ambiência é a soma dos ambientes (2009, p. 103-105).
} 
Criar Educação, Criciúma, v. 9, no 3, ago/dez. 2020 - PPGE - UNESC - ISSN 2317-2452 por exemplo, recuso, refuto, repilo, deserdo, rasuro, desisto (LEMINSKI, 1989, ps. 36-37).

O percurso instaurado se configura rizomaticamente na medida em que descentra a linguagem para outros movimentos que se constituem nesse insólito. Não apenas a linguagem, mas, como já dito o pensar, corroborando a necessidade de expandir a linguagem para outras áreas, pois,

Num rizoma, cada tração não remete necessariamente a um traço linguístico: cadeias semióticas de toda natureza são aí conectadas a modos de codificação muito diversos, cadeias biológicas, políticas, econômicas, etc., colocando em jogo não somente regimes de signos diferentes, mas também estatutos de estados das coisas. [...]. Cada cadeia semiótica é como um tubérculo que aglomera atos muito diversos, linguísticos, mas também perceptivos, mímicos, gestuais, cogitativos. Um método do tipo rizoma é obrigado a analisar a linguagem efetuando um descentramento sobre outras dimensões e outros registros". (DELEUZE E GUATTARI, 1995, p.15-16).

É nessa perspectiva que a sensação e o experimentar vão se definindo como elementos fundamentais para a construção de sentidos, visto que a produção da linguagem implica múltiplas relações, descentramentos e vozes. Mas de que vozes se trata, se o personagem se encontra sozinho nos trópicos brasileiro? Não se trata simplesmente da voz no sentido de sua sonoridade, mas os liames que ela estabelece com o corpo físico e com o corpo social.

Ainda que esteja aparentemente só, o personagem busca diálogo com as vozes do cogito que ele tenta reorganizar, inicialmente, e, justamente por isso, percebe o quanto a racionalidade cartesiana, bem como a elaboração linguística se esgotam em si mesmas, haja vista o elipsar do "Eu" de Descartes ao afirmar não ser máquina, nem bicho. Dito de outro modo, é graças às aporias que Cartesius se constituirá como signo poético do fazer e do abstrair, o que significa também um educar dos sentidos a partir da experiência.

Em que pese o possível diálogo entre ficção e realidade no que toca à experimentação, cabe trazer aqui uma hipótese interessante sobre o Descartes histórico. Trata-se do tempo em que estudou no colégio jesuíta La Fleche, quando, 
Criar Educação, Criciúma, v. 9, no 3, ago/dez. 2020 - PPGE - UNESC - ISSN 2317-2452

ainda jovem, desencantado pela provável rigidez da doutrina imposta, desejou experimentar o mundo, conforme anuncia abaixo,

E, resolvendo-me a não procurar mais outra ciência a não ser a que pudesse descobrir em mim próprio, ou então no grande livro do mundo, empreguei o resto da minha mocidade a viajar, a ver cortes e exércitos, a frequentar pessoas de diversos feitios e condições, a recolher diversas experiências, a experimentar-me a mim próprio (DESCARTES, 1990, p. 10).

Guardadas, obviamente, as especificidades do discurso histórico, real e as da ficção, é possível pensar em alguma proximidade entre o educar a partir da experiência por parte do personagem Cartesius e o desejo manifestado pelo personagem histórico.

Sobre a enunciação de Descartes e a linguagem de Cartesius, mais experimental, nota-se que cada qual revela um espírito poético a seu modo; o primeiro no desejo de experimentar a si próprio através do livro do mundo; 0 segundo revelando tal espírito mediante uma postura mais voltada para a percepção dos eventos que circunscrevem seu novo cotidiano, para o qual outra voz se anuncia.

\section{2 - A voz e(m) performance de Cartesius: razão e sensibilidade}

A compreensão do humano remete à voz porque esta é da ordem do reconhecimento do outro e de si, da manifestação de relações de poder e da expressão dos valores das diferentes culturas. Nas palavras do pesquisador das poéticas do Medievo, Paul Zumthor "a voz é verdadeiramente um objeto central, um poder, representa um conjunto de valores que não são comparáveis a nenhum outro, valores fundadores de culturas, criadores de inumeráveis formas de arte". (2005, p. 61).

No que diz respeito a Cartesius, trata-se de uma voz que se constitui para além da sintaxe preconizada pela linearidade, já que o personagem vai se revelando multifacetado diante dos caminhos que rizomaticamente cartografa, visto que, 
Os entes da razão estão indo a caminho da execução, acontece algo daquilo que eu conto. Uns dizem coisas que a gente não sabe o que dizer. Dado que isso já foi feito, dito que já deu fruto. Isso é coisa sob controle do passado remoto. (LEMINSKI, 1989, p.21)

Nota-se o quanto o passado vai cedendo lugar ao inovador, seja no linguajar, seja no pensamento e, desse modo, Cartesius adquire uma voz capaz de se dizer diante do insólito e das novas experiências constituídas rizomaticamente, pois, tal qual aponta o conceito deleuziano, seu pensamento não é mais arborescente, mas uma cadeia de articulações que ora territorializam, ora desterritorializam os espaços pelos quais transitam.

De modo semelhante, sua voz, agora aberta ao novo, migra de um ponto a outro sem necessidade de uma regra que a conduza, visto que o experimentar se sobrepõe à racionalidade cartesiana e, nesse contexto, o personagem acaba por educar-se cada vez mais para a sensibilidade.

É pertinente dizer que a voz redimensionada remete ao descentramento derivado do rizoma conforme apontado por Deleuze e Guattari (1995), e que, no caso do personagem, tem a ver com a voz no âmbito de sua fisicalidade, ou massa sonora, e com a voz social, já que se trata agora de uma voz em performance enquanto "ato de presença no mundo" (Zumthor, 2007, p. 67).

Ao operar uma linguagem que se institui no horizonte do provável, Cartesius reitera que entre a voz e a palavra encontram-se várias camadas, sendo, algumas, constituídas à margem da hipotaxe privilegiada pela taxonomia de tradição linguística e pelo pensamento supostamente linear, visto que não há linearidade no pensamento, o qual estabelece links com diferentes elementos sem necessidade de hierarquias entre eles.

Em termos de expansão de linguagem, a não linearidade tem a ver com a composição heteróclita constituída pelos diferentes grupos sociais, ou, mais especificamente, pelas diferentes vozes sociais. Em se tratando de Cartesius, a voz dialógica e expandida para uma nova linguagem, iniciada quando aportado nos trópicos, se refere à verborragia diante da angústia de saber-se desprovido de um 


\section{CRIAR EDUCAÇÃO \\ Revista do Programa de Pós-Graduação em Educação - UNESC}

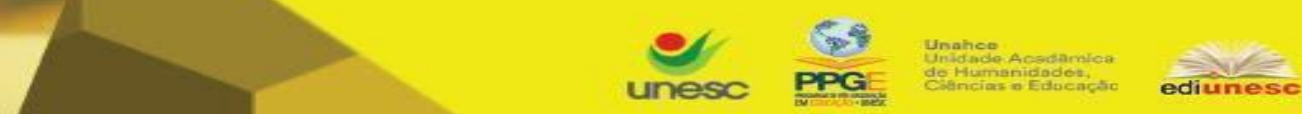

Criar Educação, Criciúma, v. 9, no 3, ago/dez. 2020 - PPGE - UNESC - ISSN 2317-2452

método que explique a razão do novo mundo às elucubrações, cada vez menos traduzível segundo a noção de início, meio e fim.

O vozerio periga ir dar em oitivas loquazes. Escuta a ponto de ouvir qualquer suspeita de murmúrio nas moitas circunvizinhas? Qualquer momento vai acabar com a luz. Talvez a exatidão seja um valor contestável, (...). Penso muita coisa junto, penso tudo de uma vez. (LEMINSKI, 1989, p. 186)

A voz, segundo Zumthor (2007) se esvai do corpo como energia, elã vital que extrapola a si mesma e se materializa e é nesse sentido que se pode dizer que ela é voz em performance, pois, "A performance é reconhecimento, A performance realiza, concretiza, faz passar algo que eu reconheço, da virtualidade à atualidade" (idem, 2007, p. 31).

Dito de outro modo, a voz em performance compreende o conhecimento adquirido pela experiência e, sem desdenhar o que se conhece previamente, ultrapassa estereótipos e dizeres cristalizados, e superando-os se renova constantemente, ou seja, cria ambiências, tal qual o faz o personagem Cartesius.

Mudam as coisas, depravam-se as palavras, palavras depravadas falam certo de coisas erradas: me depompo, falando errado. (LEMINSKI, 1989, p. 56)

Dissipei as certezas, despistei um setestrelo. Aprendi bastante: vamos desaprender, não obstante. (idem, p. 88)

Nota-se o quanto as palavras depravadas passam a falar certo, já que não necessitam de uma regra que as acolha. Do mesmo modo, despistar o setestrelo, isto é, despistar o caminho das estrelas equivale a buscar outros caminhos. Do ponto de vista da voz em performance, é exatamente isso que faz Cartesius ao destituir os entes da razão em função de um novo que não nega o anterior, mas busca desaprender como forma de se dar ao conhecimento do novo. 
Criar Educação, Criciúma, v. 9, no 3, ago/dez. 2020 - PPGE - UNESC - ISSN 2317-2452

\title{
3 - Experimento. Logo, sinto: educação e sensibilidade
}

Não é novidade que a língua é um signo de poder e dominação, haja vista que quando um povo é dominado por outro, uma das primeiras medidas é confiscar a língua para impedir a comunicação entre os falantes para evitar qualquer tipo de manifestação. Segundo o estudioso de genética Luigi Cavalli-Sforza,

\begin{abstract}
Mais de 5 mil línguas são faladas hoje em dia. Algumas poucas são usadas por centenas de milhões de pessoas, mas a grande maioria possui uma distribuição bastante restrita. Línguas faladas por menos de cem pessoas correm o risco de extinção iminente; muitas já desapareceram. (CAVALLI-SFORZA, 2003, p. 177)
\end{abstract}

A modificação é tão rápida que a taxionomia linguística não é capaz de precisar como e em que momento houve a interpenetração e a incorporação entre as diferentes línguas. Daí várias línguas de pequenas comunidades desaparecerem ou serem incorporadas por outras, o que não impede a comunicação, visto que para além da língua, existe a linguagem que expressa muito mais do que o código linguístico, já que lida com o constante experimentar, seja por sons, gestos, silêncios, entre outros códigos criados pelo homem.

Em se tratando de literatura, algumas obras, sobretudo das Vanguardas do início do século XX já propunham experimentações radicais com a língua e com a linguagem. O que Catatau anuncia, na voz de Cartesius é justamente esse nível de experimentação que torna sua linguagem mais rarefeita.

À medida que experimenta uma nova linguagem, o personagem amplia e amplifica a voz para novas ambiências que não operam dicotomias, mas, sim, complexidades diante do mosaico de sons, ruídos, palavras, gestos e outros elementos que dão novo ritmo ao que se pode chamar de aprendizado, pautado pela educação para a sensibilidade.

A própria noção de signo linguístico, sobreposta pela experimentação do personagem aponta para composições mais rizomáticas que não negam o que ele já sabe, mas que transformam esse saber em novos fios condutores para outros aprendizados. 
Criar Educação, Criciúma, v. 9, no 3, ago/dez. 2020 - PPGE - UNESC - ISSN 2317-2452

Pode-se afirmar, assim, que a educação para a sensibilidade exige o descentramento da linguagem e do pensamento para outras dimensões, o que leva a questão da educação menor, conforme aponta o filósofo Silvio Gallo, que se apropria do conceito de literatura menor de Deleuze e Guattari para pensá-la no âmbito da educação.

$\mathrm{Na}$ obra "Kafka, por uma literatura menor", os autores franceses afirmam que "as três características da literatura menor são: desterritorialização da língua, ramificação do individual no imediato-político e o agenciamento político da enunciação (DELEUZE \& GUATTARI, 1977, p.28).

O sentido de "menor" atribuído pelos filósofos à literatura é da ordem do descentramento da língua e da linguagem para outros territórios que possam ser alcançados pelas massas, e nesse contexto, confirma-se seu caráter transformador e político na medida em que se torna um ato coletivo. Uma vez descentradas, ambas, língua e linguagem, se tornam agenciamentos, ou seja, multiplicidades de dimensões que se produzem constantemente, sem necessidade de hierarquia, já que se trata de experimentação.

Em relação à Catatau, é exatamente o que faz o personagem, já que para ele, "a questão já está metodologicamente mal feita, então não adianta tentar entender em cima da hora, dado o adiantado alucinado da mesma que só vai parar daqui a um século". (LEMINSKI, 1989, p. 110).

Parece que já existe o reconhecimento de que o método não funciona naquelas plagas em que a linguagem não se configura como antes, o que o leva a desaprender como forma de instituir um novo pensar sobre o mundo, sobre si e sobre os fenômenos.

Considerando a relação entre a literatura, especificamente a obra aqui elencada, nota-se que em ambos os casos, é inviável "tentar entender em cima da hora", visto que a construção de conhecimento é um processo que não pode ser prédeterminado por métodos que se pretendam universais ou por taxonomias que fragmentem o conhecimento.

Uma possibilidade de superar essa fragmentação tema ver com a desterritorialização para outros espaços do conhecimento que se somem ao 
Criar Educação, Criciúma, v. 9, no 3, ago/dez. 2020 - PPGE - UNESC - ISSN 2317-2452

inovador e, desse modo, torna-se possível criar novas ambiências que levem em conta o fazer e o abstrair como sinônimos, levando em conta o dado experimental que os norteia.

A educação para a sensibilidade compreende o aspecto criativo e rizomático capaz de descentrar a linguagem cristalizada em direção à educação "menor", pois como asseveram os filósofos Deleuze e Guattari,

Temos que pensar a desterritorialização como uma potência perfeitamente positiva, que possui seus graus e seus limiares (epistratos) e que é sempre relativa, tendo um reverso, uma complementaridade na reterritorialização. (DELEUZE \& GUATTARI, 1995, p. 69)

Os processos de desterritorialização e reterritorialização traz em seu bojo o vislumbre do devir, sobretudo porque, entre outros fatores, é capaz de criticar o interior do processo diante de uma linguagem e um pensamento mais abertos às experimentações. Obviamente, experimentar compreende uma postura acurada sobre os elementos que constituem uma educação pautada no despertar da sensibilidade na qual estão consideradas as dimensões políticas, linguísticas, discursivas, históricas, sem os quais não se operaria uma educação rizomática.

Por isso, o pensar uma educação menor na perspectiva do despertar da sensibilidade relacionada à arte literária, como proposto, remete à não interpretação imediata, mas ao experimentar caminhos ou ambiências que venham a constituir novos devires, ou seja, "fazer da consciência uma experimentação de vida, e da paixão um campo de intensidades contínuas, uma emissão de signos-partículas" (DELEUZE E GUATTARI, 1995a, p. 76).

Dito de outro modo, uma educação menor, assim como uma literatura menor são da ordem das vozes em performance a partir das quais novos discursos se produzem. Retomando Cartesius quando ele anuncia que "mudam as coisas, depravam-se as palavras" (LEMINSKI, 1989, p. 56), observa-se o quanto as palavras depravadas são frutos de um novo olhar diante das coisas já modificadas com as quais ele se depara. Na narrativa de Cartesius, a multiplicidade de significâncias e significantes é demonstrada pela linguagem do provável e pelo 
Criar Educação, Criciúma, v. 9, no 3, ago/dez. 2020 - PPGE - UNESC - ISSN 2317-2452

continuum do movimento que o levam ao desejo de buscar a liberdade por meio do experimentar, e, portanto, dirá o personagem,

Me percebo. Triunfam. Tudo é claro, estou compreendendo. Atenção! Quero a liberdade de minha linguagem. As núpcias da Essência com a da existência. Vire-se. Quero mudar. Crio contextos. Faço parte do que eu faço. Desenvolvo uma lógica, o ritmo é a lógica. (LEMINKSI, 1989, p.58).

Não deixe o ritmo morrer, um ritmo que morre, diminui o mundo. (idem, 1989,p. 67)

Perceber-se tem a ver com assumir-se como voz de um novo olhar sobre o que até então se lhe apresentava como certo e sabido e que não cabe mais nesse ritmo em que encontra, a saber, o ritmo da nova linguagem e nesse sentido, "o único subterfúgio é não se deixar envolver, e procurar refúgio num desses labirintos que vem vindo aí. $A x t / y x=y$ ! Observa o avesso e o atravessa" (LEMINSKI, 1989, p. 110).

Ao educar-se para a sensibilidade, o personagem rizomatiza-se como voz em performance devido ao fato de que se torna meio e mensagem simultaneamente já que institui um novo ritmo para sua fala confirmando que "muita voz diz o som do além, narrar incentiva, e "falar das coisas é deixá-las ir sendo, passando de lá delas para nós" (LEMINSKI, 1989, ps.59-60).

Nota-se tratar o personagem da experiência que leva sua voz para além do pré-estabelecido na medida em que o falar significa a liberdade de ser. Deliberadamente provocativo, Cartesius traz a inconformidade para com os ditames do recta ratio, e não se submete às formas cristalizadas de registro, o que implica uma educação para a sensibilidade pautada em uma voz cuja dimensão rizomática que pode nortear a construção de conhecimento.

No que concerne à educação menor e à literatura menor, nota-se a produção de agenciamentos, de multiplicidades possíveis quando literatura e educação se encontram, pois, como aponta Gallo (2013) o sentido de menor significa s subversão de ambas para que se tornem veículos de desagregação de si próprias, ou como 
dizem Deleuze e Guattari, descentradas de si mesmas, o que pode levar à produção das multiplicidades.

Segundo Gallo "uma educação menor é um ato de revolta e de resistência. Resistência contra os fluxos instituídos, resistência às políticas impostas" (GALLO, 2013, p.64), e por isso mesmo, uma liberdade de linguagem, sem a qual não se pode pensar em educar. Do ponto de vista da educação para a sensibilidade, tal educação "aposta nas multiplicidades que rizomaticamente se conectam e interconectam, gerando novas multiplicidades" (idem, p.69).

Compreender a educação para a sensibilidade deriva do ato de experimentar novos trajetos, ainda que inicialmente pareçam "erráticos" como ocorre na saga do personagem de Catatau. Ao fazê-lo, torna-se possível desvelar o potencial criativo a partir do qual os "enganos deleitáveis", considerando os que se apresentam para Cartesius possa efetivar-se como cartografias de possibilidades.

\section{Considerações finais}

Longe de esgotar o tema tão rico e caro à educação, sobretudo no que toca à sensibilidade, pode-se dizer, a partir da linguagem metafórica presente na obra literária, que é possível superar o contexto fragmentário que parece ainda ocorrer no âmbito da educação mediante a desterritorialização da voz e do pensamento, os quais, uma vez assumidos como posturas de ordem política e discursiva, tornam-se capazes de rizomatizarem-se para outras dimensões de registros, criando ambiências em devir.

Educar para a sensibilidade, especialmente na contemporaneidade, atravessa questões como arte, linguagem, entre outros signos que operam códigos nem sempre previstos por taxionomias, o que confirma sua riqueza como rizomas pertinentes à construção de conhecimento.

Retomando a questão norteadora sobre como o inusitado da língua, da linguagem e do pensamento presente na obra literária, no caso, o Catatau, rizomatiza para outros territórios, pode-se confirmar a hipótese de que as aporias e angústias causadas pela nova linguagem à qual Renatus Cartesius está submetido, 
Criar Educação, Criciúma, v. 9, no 3, ago/dez. 2020 - PPGE - UNESC - ISSN 2317-2452

levam-no a construir novos caminhos, descentrados de métodos cristalizados, que não mais respondem à dimensão criativa que o personagem estabelece com os territórios que cartografa e que o levam a criar novas ambiências de sentido.

No contexto da educação, confirma-se que a educação para a sensibilidade é sinônimo da educação menor, pois, uma vez desterritorializada, redimensiona as vozes alcançando o potencial criativo e político que circunscreve ou deveria circunscrever o ato de educar. Tendo em vista que tal ato se faz pelas vozes e, portanto, pelo coletivo sob o qual deve pairar a educação, pode-se inferir que somente nesse sentido, a voz se confirma como performance, na medida em que se reconhece como o saber fazer nos diferentes âmbitos.

É pertinente, dizer, então, que o diálogo entre literatura e educação, é espaço profícuo para a criação de novas ambiências nas quais o signo poético presente na obra literária articula-se à uma educação para a sensibilidade, desvelando o potencial criativo e de resistência de ambas na construção de conhecimento pautado na voz dos sujeitos mais do que nos ditames metódicos. Novamente, cabe reiterar que a proposta não é a de negar o caminho já construído, mas antes, somá-lo ao inovador, visando possibilidades epistemológicas nas quais o fazer e o abstrair sejam sinônimos de novos aprendizados.

\section{Referências}

AZEVEDO, Wilton. Interpoesia: o início da escritura expandida. Tese de PósDoutorado. Paris: Université Paris 8 - Sorbonne -Laboratoire de Paragraphe, 2009.

DELEUZE, Gilles; GUATTARI, Félix. Mil platôs: capitalismo e esquizofrenia. Vol.1. Trad. Aurélio Guerra Neto e Célia Pinto Costa. Rio de Janeiro: Ed. 34, 1995.

DELEUZE, Gilles; GUATTARI, Félix. Mil platôs: capitalismo e esquizofrenia. Vol.2. Trad. Ana Lúcia de Oliveira e Lúcia Cláudia Leão. Rio de Janeiro: Ed. 34, 1995a.

DESCARTES, René. Discurso do Método- As paixões da Alma. Lisboa: Livraria Sá da Costa Editora, 1990.

GALLO, Silvio. Deleuze \& a Educação. 3ª ed. Belo Horizonte-MG: Autêntica, 2012. 


\section{CRIAR EDUCAÇÃO}

Revista do Programa de Pós-Graduação em Educação - UNESC

Criar Educação, Criciúma, v. 9, no 3, ago/dez. 2020 - PPGE - UNESC - ISSN 2317-2452

LEMINSKI, Paulo. Catatau. Porto Alegre, RS: Sulina, 1989.

ZUMTHOR, Paul. Performance, recepção, leitura. Trad. Jerusa Pires Ferreira, Suely Fenerich. São Paulo: Cosac Naify, 2007.

Recebido em julho de 2020 Aprovado em outubro de 2020 